\title{
Research on Online Control for Product Development Process
}

\author{
X. Y. Li \\ School of Mathematics and Computer Science \\ JiangHan University \\ Wuhan 430056, P.R. China \\ e-mail: 813809236@qq.com
}

\begin{abstract}
-for implementing the online control of product development process in Micro-Plant, an integration control platform is proposed based on web service technology. Professional software such as G2, GAMS, Matlab, are wrapped as web services based on multi-agent technology, and the web service named Data_Service is given to implement the data communication among different web services, then we can control and optimize the product development process in Micro-Plant. Finally the practicability and validity of the integration control platform are verified through the application in the product development of Nipagin ester.
\end{abstract}

Keywords-online control; web service; fault diagnose; linear regression; online optimization

\section{INTRODUCTION}

Researching how to shorten the development cycle of chemical with high value-added, to a corporation, it means the increase of economic benefit [1,2]. For researching product development process, a product development platform named Micro-Plant has been built in author's laboratory based on web service technology, and the simense winCC is used to control the product development process. During the product development process in Micro-Plant, we can use the G2 Service to find the abnormal condition by fault diagnose. For online control the product development process, firstly, we use the Matlab Linear Regression Service to analyze the relationship among different variables, and then we can get the goal function which describes the relationship among variables. Based on the goal function, we can create GAMS optimization model and get the optimization operation condition at any moment, and then we can control the product development process with the optimization condition [3, 4].

The reminder of this paper is structured as in the following: section 2 gives an overview on service oriented architecture; section 3 gives an introduction on the online control platform; section 4 gives a case study, and finally, section 5 contains the conclusion.

\section{WEB SERVICE OVERVIEW}

Web services are services that are made available from a business's web server for web users or other web -connected programs. Providers of web services are generally known as application service providers. Web services range from such major services as storage management and customer relationship management down to much more limited services such as the furnishing of a stock quote and the checking of bids for an auction item. [5, 6] The accelerating creation and availability of these services is a major web trend. [7, 8]

Users can access some web services through a peer-topeer arrangement rather than by going to a central server. [9, 10] Some services can communicate with other services and this exchange of procedures and data is generally enabled by a class of software known as middleware. [11,12] Services previously possible only with the older standardized service known as electronic data interchange increasingly are likely to become web services. $[13,14]$ Besides the standardization and wide availability to users and businesses of the Internet itself, web services are also increasingly enabled by the use of the extensible markup language as a means of standardizing data formats and exchanging data. [15, 16] $\mathrm{XML}$ is the foundation for the web services description Language. As web services proliferate, concerns include the overall demands on network bandwidth and, for any particular service, the effect on performance as demands for that service rise. $[17,18]$ A number of new products have emerged that enable software developers to create or modify existing applications that can be published as Web services.

\section{The ONLINE CONTROL PlatForm For PRODUCT DEVELOPMENT PROCESS}

\section{A. The Framework For The Online Control Platform}

Researching how to shorten the development cycle of chemical with high value-added, to a corporation, it means the increase of economic benefit. For researching product and process development, a product development platform named Micro-Plant has been built in author's laboratory. In order to control the product development process in the Micro-Plant, an online control platform has been developed, and uses it to implement the real-time control and optimization of product development process. The framework of the system is show in Fig. 2.

In the system, we use Simense WinCC to control the Micro-Plant directly. There are four key web services in the control platform too; there are implemented by encapsulating Matlab, GAMS, OPC Server and G2 separately. According to real-time data, the Matlab_Service can analyze the linear relationship among different variables and return a goal function, and the goal function describes the relationship between the maximal output of goal product and the variables of reaction conditions. Based on the goal function 
and the allowed range reaction conditions, the control platform will create GAMS optimization model, and we can call GAMS Service to solve the optimization control model to get the optimal reaction conditions, finally we can change the reaction conditions on Micro-Plant to the optimzal status, this ensures the product development process on the optimal reaction conditions. During the product development process,

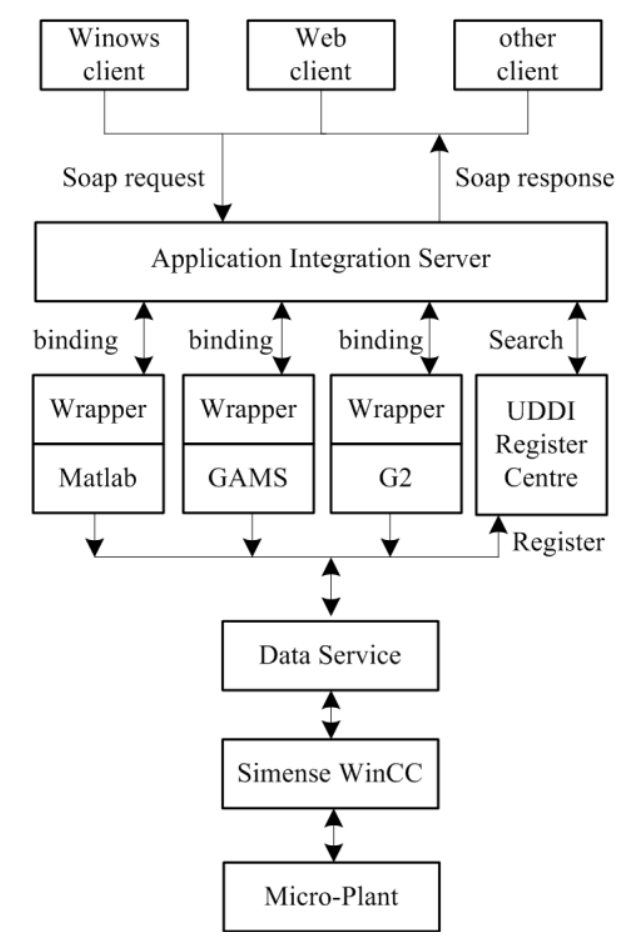

Figure 1. The framework of the integration control system

some abnormal conditions will appear, so we must call the G2 Service to find them and stop the product development process on the abnormal conditions.

\section{B. Key Web Services For The Control System}

In the control platform, there are four basic web services, based on the cooperation among them; we can implement the control and optimization of product development process in Micro-Plant. Follows give a simple introduction for the four web services.

- Data_Service. Data_Service is the basic service in the platform which connects the control platform and Micro-Plant. As a middleware, Data_Service contains many interfaces with external systems, which usually are based on single or multiple techniques of database, OPC and CORBA. Based on Data_Service, the control platform can get the values of time-varying variables form the Micro-Plant, and adjust the key variables according to the optimization strategy. In Data_Service, OPC is the most important technique, which is based on Microsoft OLE, COM/DCOM techniques.
- Matlab_Service. There is powerful function in Matlab, such as data analysis, data emendation, and image process. In the control platform, it is encapsulated as a web service named Matlab_Service, and its basic function is to get realtime data from Data_Service and implement the data linear regression, finally, we can get the goal function which describes the relationship among different variables.

- G2_Service. G2 is a real-time expert system, which is developed by Gensym Corporation in America. It is widely used in industry areas, such as fault diagnosis, advanced control, device optimization, scheduling, environment monitoring, and G2 integrates expert system, software and net technique. In the control platform, the expert system of G2 is encapsulated to build G2_Service. G2 expert system provides G2-ODBC-Service, so the data transmission between G2_Service and expert system is possible. Based on the strong rule reasoning capacity, G2_Service implements fault diagnosis and fault analysis for product development process.

- GAMS_Service. GAMS is specifically designed for modeling linear, nonlinear and mixed integer optimization problems. In the control platform, for getting the maximal output of goal chemical, it is used to implement the real-time optimization of reactive condition. As a web service, GAMS_Service can work out the optimal reactive condition, then based on it, the operator can change the real reactive condition in Micro-Plant.

\section{Cooperation of Web Services In The Platform}

The cooperation model of the four key web services in the control system is shown is Fig. 3. Data_Service is the middleware between optimization control platform and product development system; therefore, the values of variables of G2_Service, Matlab_Service and GAMS_Service need to be access by Data_Service. Matlab_Service uses the real-time values of main control variables to regress and establishes the control model of product development process, and the control model is sent to GAMS_Service. GAMS_Service is used to work out the optimal values of operation conditions at certain moment, which will be transmitted to WinCC by Data_Service. And in WinCC, the reaction conditions will be adjusted to the optimal point. G2_Service gets the real-time values of control variables through Data_Service, and verifys if there are faults happened in the product development process.

\section{The Workflow of Optimization Control Platform}

As follow is the workflow of the integration control system for Micro-Plant:

- (1) Operator assigns hostname and product type of product development system named WinCC.

- (2) Operator assigns the data accessing technique of Data_Service, such as OPC, database, or CORBA.

- (3) Operator assigns the optimization control model for product development process, and the model 
should be verified by GAMS. If the model doesn't work, operator needs to modify or change it.

- (4) The application server tells the operator which web services will be called in the control system.

- (5) With the affirmation of operator, application server will generated process definition document and save it.

- (6) Based on the cooperation among the control system and winCC, the product development process is controlled and optimized in Micro-Plant. In the process of product development, the control model is optimized based on the product data intelligently.

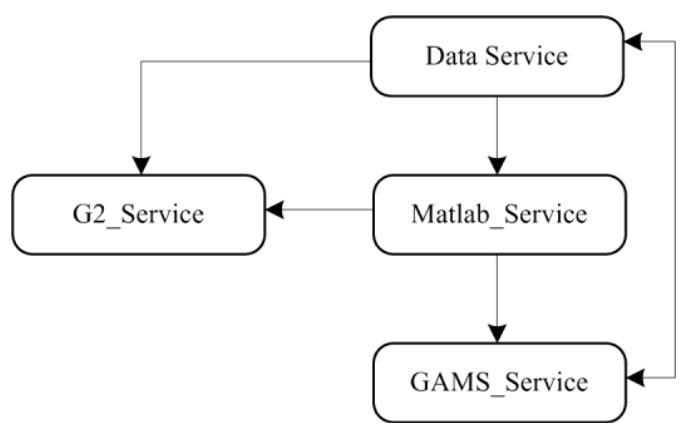

Figure 2. Cooperation of web service during optimization and control

\section{CASE STUdY}

Nipagin ester is one of the case studies in the Micro-Plant. Nipagin ester is a new anti-mildew and antiseptic agent with the best inhibiting effect on aflatoxin in food, dring, cosmetics and medicine. The reaction equation is as following:

$$
\mathrm{C}_{7} \mathrm{H}_{6} \mathrm{O}_{3}+\mathrm{CH}_{3} \mathrm{CH}_{2} \mathrm{OH} \rightarrow \mathrm{C}_{9} \mathrm{H}_{10} \mathrm{O}_{3}+\mathrm{H}_{2} \mathrm{O}
$$

According to the analytic result in the chemic laboratory, for getting the maximal output of Nipagin ester, the control model is built, the goal function is as following:

$$
y=81981 x_{1}^{-1.444} x_{2}^{0.341} x_{3}^{0.534} x_{4}^{-0.147} x_{5}^{-0.393} x_{6}^{-0.027}
$$

In the control model, there are seven variables; the means of the seven variables are as follows: $\mathrm{y}$ is the output of Nipagin ester, $\mathrm{x}_{1}, \mathrm{x}_{2}, \mathrm{x}_{3}, \mathrm{x}_{4}, \mathrm{x}_{5}, \mathrm{x}_{6}$ are the quantity of $\mathrm{C}_{2} \mathrm{H}_{5} \mathrm{OH}$ which has participated in reaction, the quantity of $\mathrm{C}_{7} \mathrm{H}_{6} \mathrm{O}_{3}$ which has participated in reaction, the pressure in reactor, the temperature in reactor, the $\mathrm{pH}$ value in the reactor, and the stirrer speed in reactor respectively. The structure of MicroPlant is shown in Fig.4.

As shown in Fig.5, Matlab_Service can analyze the linear relationship among $\mathrm{x}$ and $\mathrm{y}$, and according the analysis, we can create the optimization control model. According to the control model, for getting the maximal output of Nipagin ester, we can work out the optimal value of $\mathrm{x}_{\mathrm{i}}(\mathrm{i}=1,2,3,4,5,6)$ by GAMS_Service, as shown in Fig.6.. When the reaction is processing in Micro-Plant, we can get the real values of $\mathrm{x}$ from OPC XML DA Server, and we can set the domain of $\mathrm{x}$ near the real-time value, the we use the GAMS_Service to work out the optimal value of $x$, finally, the operator can set current values of $\mathrm{x}$ in Micro-Plant to the optimal value, through this way, the whole reaction will process along the goal for getting the maximal output of Nipagin ester.

As show in Fig.7, for finding abnormal reaction condition and equipment faults in Micro-Plant, a web service is developed based on G2 develop platform. In the interface, the temperature of Reactor10 and Reactor20 is monitored, and the trend curve of temperature is shown, to the two reactors, when the temperature reaches the maximal value that is set by operator, the web service will display the warning message, and at the same time, according to inferring based on rules in rule-database, the operator will get some advices from the web service on how to solve the current problem.

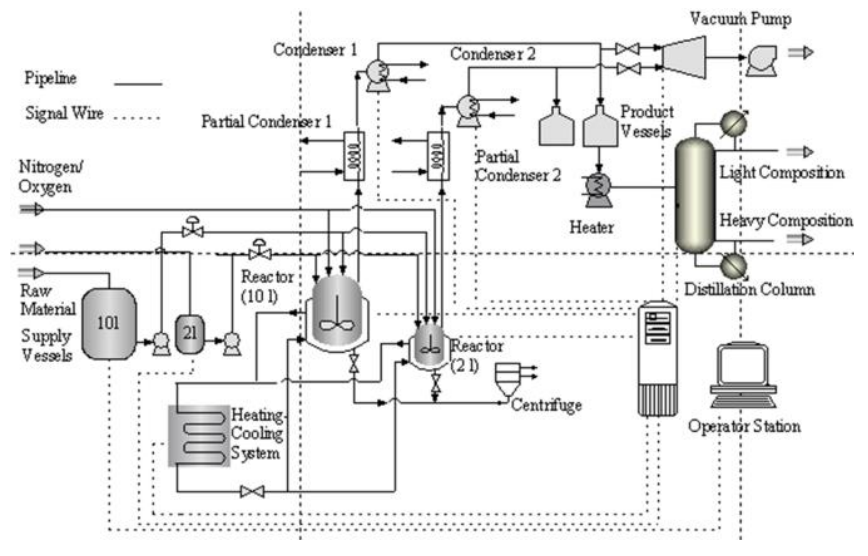

\begin{tabular}{|c|c|c|c|c|c|c|}
\hline Refresh Data & Date From & & :49:38 & To & 14:32:11 & Linear Programming by matlab \\
\hline & \multicolumn{6}{|c|}{ C7h603 C2h6O C9h1002 Temperature Pressure pH Value Mixing Speed } \\
\hline \multirow{3}{*}{$\begin{array}{c}\text { Linear } \\
\text { Programming }\end{array}$} & 310 & 500 & 206.62 & 100 & 1.1 & 100 \\
\hline & 310 & 500 & 233.36 & 100 & 1.1 & 100 \\
\hline & 310 & 500 & 207.91 & 100 & 1.1 & 100 \\
\hline \multirow{3}{*}{ Fault Diagnose } & 310 & 500 & 210.48 & 100 & 1.1 & 100 \\
\hline & 310 & 500 & 232.26 & 100 & 1.1 & 100 \\
\hline & 310 & 500 & 227.42 & 100 & 1.1 & 100 \\
\hline \multirow{2}{*}{$\begin{array}{c}\text { GAMS } \\
\text { Optimization } \\
\end{array}$} & 310 & 500 & 211.53 & 100 & 1.1 & 100 \\
\hline & \multirow{3}{*}{\multicolumn{6}{|c|}{$\begin{array}{l}\text { The linear regression result is: } \\
\mathrm{Y}=0.010^{*} \mathrm{x} 1+0.08^{*} \times 2+0.001 * \mathrm{x} 3+90^{*} \times 4+35.529 * \mathrm{x} 5-0.019^{*} \mathrm{x} 6 \\
\text { Description: } \\
\mathrm{Y} \text { : the weight of } \mathrm{c} 9 \mathrm{~h} 10 \mathrm{o} 2 \\
\mathrm{x} 1: \mathrm{c} 7 \mathrm{~h} 603 \\
\mathrm{x} 2 \mathrm{c} 2 \mathrm{~h} 6 \mathrm{0} \\
\mathrm{x} 3 \text { :temperature } \mathrm{x} 4 \text { : pressure, } \mathrm{x} 5 \text { : ph Value, } \mathrm{x} 6 \text { : mixing speed }\end{array}$}} \\
\hline System Setup & & & & & & \\
\hline Connection Test & & & & & & \\
\hline
\end{tabular}

Figure 3. The structure of Micro-Plant

Figure 4. The linear regression of Matlab Service 


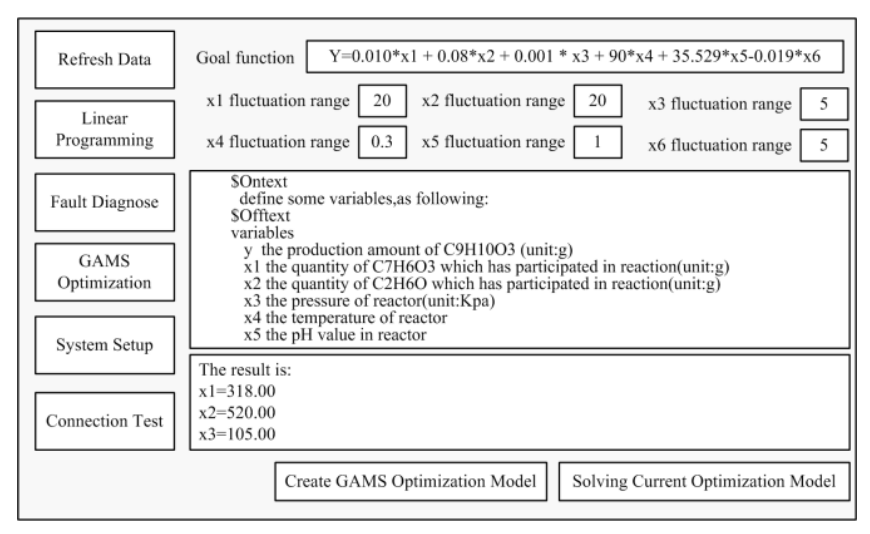

Figure 5. The solving of online optimization model of GAMS Service

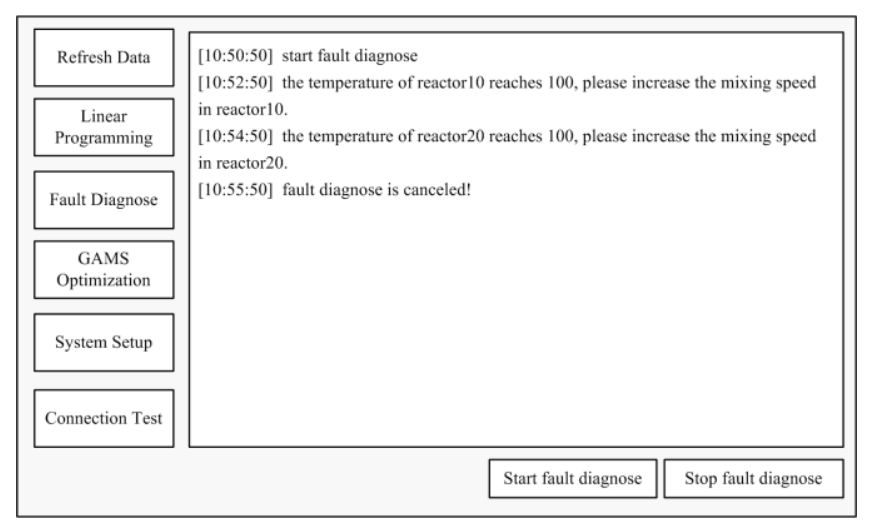

Figure 6. The fault diagnose of G2 Service

\section{CONCLUSION}

For researching the online control of product development process in Micro-Plant, an integration control platform is proposed based on web service technology in the paper, professional software such as G2, GAMS, Matlab, are wrapped as web services based on multi-agent technology, and these software running on different platform can cooperation to implement the online control of product development process, and they can communicate with SOAP message. Finally, the practicability and validity of the integration control platform are verified through the application in the product development of Nipagin ester.

\section{REFERENCES}

[1] S. Ramachandran, L. Santapoor, H. Rayudu, "Functional Based Testing in Web Services Integrated Software Applications," Communications in Computer and Information Science Volume 133, pp.130-138, 2011.

[2] L.Z. Zeng, "Dynamic composition and optimization of Web services," Distributed and Parallel Databases, Volume 24, Issue 1-3, pp.45-72, 2008.

[3] C. Cappiello, M. Comuzzi, P. Plebani, "On Automated Generation of Web Service Level Agreements," Lecture Notes in Computer Science Volume 4495, pp.264-278, 2007.

[4] L. Baresi, C. Ghezzi, S. Guinea, "A framework for the deployment of adaptable web service compositions," Service Oriented Computing and Applications, Volume 1, Issue 1, pp.75-91, 2007.
[5] F. Klan, B. K.Ries, "A Conversational Approach to Semantic Web Service Selection," Lecture Notes in Business Information Processing Volume 85, pp.1-12, 2011.

[6] A. Chiabai, L. Rocca, L. Chiarullo, "A Service Quality Model for Web-Services Evaluation in Cultural Heritage Management," Lecture Notes in Computer Science Volume 6783, pp.227-242, 2011.

[7] W. Binder, I. Constantinescu, B. Faltings, "A Directory for Web Service Integration Supporting Custom Query Pruning and Ranking," Lecture Notes in Computer Science Volume 3250, pp.87-101, 2004.

[8] Z. Azmeh, M. Huchard, C. Tibermacine, "Automatic Web Service Tagging Using Machine Learning and WordNet Synsets," Lecture Notes in Business Information Processing Volume 75, pp.46-59, 2011.

[9] S. Overhage, P. Thomas, "WS-Specification: Specifying Web Services Using UDDI Improvements," Lecture Notes in Computer Science Volume 2593, pp.100-119, 2003.

[10] Z.M, Du, "Online simulation and optimal control of ice storage air conditioning systems," Shanghai Jiaotong Daxue Xuebao/Journal of Shanghai Jiaotong University, 43(10), pp.1595-1600, 2009.

[11] J. G. Santos, "A study on the spectral changes of reactive textile dyes and their implications for online control of dyeing processes," Coloration Technology, 125(1), pp.8-13, 2009.

[12] Y.T. Chang, Y. Lai, "Online parameter tuning technique for predictive current-mode control operating in boundary conduction mode," IEEE Transactions on Industrial Electronics, 56(8), pp.32143221, 2009.

[13] F. Jian, "The rental-type application system based on web service," International Seminar on Business and Information Management,pp.161-164,2009.

[14] L. Boncaqni, C. Centioli, "A Web Services based system for the distribution of live information at the FTU fusion experiment," Fusion Engineering and Design, 88(6), pp.475-479,2009.

[15] H. Li, "Online optimization design of fuzzy controllers based on hierarchicgenetic algorithm," Systems Engineering and Electronics, 31(4), pp.911-915,2009.

[16] W. Michael, "Online control of the injection molding process based on process variables," Advances in Polymer Technology, 28(2), pp.65-76,2009.

[17] B. Michael, "Introduction to Service-Oriented Modeling," ServiceOriented Modeling: Service Analysis, Design, and Architecture. Wiley \& Sons. ISBN 978-0-470-14111-3, pp.3-3,2008.

[18] B. Michael. "SOA Modeling Patterns for Service-Oriented Discovery and Analysis," Wiley \& Sons.ISBN 978-0-470-48197-4,pp.390$391,2010$.

[19] T.Shan, "Building a Service-Oriented eBanking Platform," First IEEE International Conference on Services Computing (SCC'04), pp.237244,2004 . 